\title{
Selective Activation of Deep Layer (V-VI) Retrohippocampal Cortical Neurons during Hippocampal Sharp Waves in the Behaving Rat
}

\author{
J. J. Chrobak and G. Buzsáki
}

Center for Molecular and Behavioral Neuroscience, Rutgers, The State University of New Jersey, Newark, New Jersey 07102

The coordinated activity of hippocampal neurons is reflected by macroscopic patterns, theta and sharp waves (SPW), evident in extracellular field recordings. The importance of these patterns is underscored by the ordered relation of specific neuronal populations to each pattern as well as the relation of each pattern to distinct behavioral states. During awake immobility, consummatory behavior, and slow wave sleep, CA3 and CA1 neurons participate in organized population bursts during SPW. In contrast, during theta-associated exploratory activity, the majority of principle cells are silent. Considerably less is known about the discharge properties of retrohippocampal neurons during theta, and particularly during SPW. These retrohippocampal neurons (entorhinal cortical, parasubicular, presubicular, and subicular) process and transmit information between the neocortex and the hippocampus. The present study examined the activity of these neurons in freely behaving rats during SPW (awake immobility) as well as theta (locomotion and REM sleep).

A qualitative distinction between the activity of deep ( $V$ VI) and superficial (II-III) layer retrohippocampal neurons was observed in relation to SPW as compared to theta. Deep layer retrohippocampal neurons exhibited a concurrent increase in activity during hippocampal SPW. In contrast, deep layer neurons were not modulated by the prominent theta oscillations observed throughout the hippocampus and entorhinal cortex. On the other hand, superficial layer retrohippocampal neurons were often phase-related to theta oscillations, but were surprisingly indifferent to the SPWassociated population bursting occurring within the deep layers.

These findings indicate a concerted discharge of the hippocampal and retrohippocampal cortices during SPW that includes neurons within CA3, CA1, and subiculum as well as neurons in layers $\mathbf{V}-\mathbf{V} \mathbf{I}$ of the presubiculum, parasubiculum, and entorhinal cortex. Further, they suggest a temporal discontinuity in the input/output relations between the hippocampus and retrohippocampal structures. We suggest that SPW-associated population bursts in hippocampal and retrohippocampal cortices exert a powerful depolarizing ef-

\footnotetext{
Received Dec. 7, 1993; revised Mar. 28, 1994; accepted Apr. 13, 1994.

This work was supported by NIH (NS27058, 28121), HFSP, and Whitehall Foundation (G.B.), and an Alzheimer's Association/NJ Health Care Facilities Association award to J.J.C. We thank R. Urioste and M. Hsu for their help in performing these studies, as well as Drs. A. Bragin and H. Read for ever helpful discussions and commentary on the manuscript.

Correspondence should be addressed to G. Buzsáki, CMBN, Rutgers University, 197 University Avenue, Newark, NJ 07102.

Copyright (c) 1994 Society for Neuroscience $0270-6474 / 94 / 146160-11 \$ 05.00 / 0$
}

fect on their postsynaptic neocortical targets and may represent a physiological mechanism for memory trace transfer from the hippocampus to the neocortex.

IKey words: hippocampus, entorhinal cortex, theta, sharp waves, oscillations, memory, temporal lobe epilepsy, Alzheimer's disease]

Retrohippocampal structures [entorhinal cortex (EC), parasubiculum, presubiculum, and subiculum] process and transmit information between the neocortex and the hippocampus. The electrophysiology of these structures has received scant attention despite their importance as a substrate for memory (Amaral, 1987; Zola-Morgan et al., 1989; Squire, 1992) and as focal point for the pathophysiology of dementia (Hyman et al., 1984; Van Hoesen et al., 1991) and temporal lobe epilepsy (Rutecki et al., 1989; Jones and Lambert, 1990; Paré et al., 1992). The present study examined the discharge patterns of neurons within these structures in relation to the predominant field potentials observed within the hippocampus in conscious rodents, sharp waves (SPW) and theta.

The laminar arrangement of the rodent hippocampus provides for highly discernible macroscopic patterns in extracellular field recordings. Field potentials, which reflect synchronized inputs upon neuronal elements, serve as temporal frameworks for coordinating neural activity. Elaboration of the neuronal types and firing patterns during such potentials can serve as building blocks for assessing function (Churchland and Sejnowski, 1992; Gray, 1993; Steriade et al., 1993). The activity of distinct populations of hippocampal neurons is predicated on the occurrence of two distinct field potentials within the hippocampus, sharp wave (SPW) and theta. These field potentials reflect the influence of distinct afferent inputs on hippocampal neurons (Buzsáki et al., 1983; Buzsáki, 1986). The importance of these potentials is underscored by the ordered relation of specific neuronal populations to each pattern as well as the relation of each pattern to specific behavioral states. This ordered mapping suggests that the SPW and theta states reflect operationally distinct states of the hippocampus.

The SPW is a large-amplitude (1-3 mV), aperiodic field potential observed in stratum radiatum of the CA1 pyramidal cell field (Buzsáki, 1986, 1989; Suzuki and Smith, 1987) that occurs during awake immobility, consummatory behavior, and slow wave sleep. These sharp transient waves $(40-100 \mathrm{msec})$ result from the excitation of the apical dendritic field of CAl neurons by their CA3 Schaffer collateral input. The SPW, thus, is a field potential in CAl arising from a population burst of CA3 pyramidal cells. Intrinsic neuronal properties and an extensive system of recurrent collaterals (Ishizuka et al., 1991; Li et al., 
1993) allow CA3 neurons to participate in synchronized populations bursts (cf. Traub and Miles, 1991). Associated with this CA1 radiatum field potential is an organized population burst of CA1 neurons (Buzsáki, 1986, 1989; Suzuki and Smith, 1985, 1987). While SPWs are aperiodic, they are coincident with a high-frequency $(200 \mathrm{~Hz})$ oscillation within stratum pyramidale (Buzsáki et al., 1992) to which pyramidal and interneuronal firing is phase related. These oscillations, coincident with the SPW, entrain the activity of pyramidal and interneurons within the CAl subfield during each SPW.

An alternate macroscopic pattern, theta, occurs during alert attention and exploratory activity. In the rodent, theta correlates prominently with, but is not necessarily defined by, locomotor activity. Theta is one of the most prominent synchronizing rhythms $(6-12 \mathrm{~Hz})$ observed in the intact CNS (Green and Arduini, 1954; Grastyán et al., 1959; Bland and Colom, 1993). Synchronous field potentials and/or phase-related neuronal activity can be observed in the hippocampus, EC (Alonso and Garcia-Austt, 1987a,b; Alonso and Llinás, 1989; Stewart et al., 1992), septum (Petsche et al., 1962), hypothalamic nuclei (Kirk and McNaughton, 1991), brainstem nuclei (Vertes, 1986; Kocsis and Vertes, 1992), and other structures in several mammalian species including rat, rabbit, cat, monkey, and human (cf. Bland and Colom, 1993). Theta oscillations entrain the firing pattern of hippocampal and entorhinal cortical neurons and in so doing coordinate their interactions with neurons in many brain structures (as listed above).

The driving forces behind hippocampal theta are intrinsic membrane currents (Alonso and Llinás, 1989; Klink and Alonso, 1993) and local circuit interactions that allow them to resonate to a beat driven by rhythmic afferent input (Traub et al., 1992), including the predominant medial septal input (Petsche et al., 1962). The synchronous fluctuations in the membrane potential of pyramidal and granule cells, which underlie theta, are generated by the synchronous excitation of the distal dendrites (EPSPs) preceded closely in time by an inhibition of the soma (IPSPs) of pyramidal and granule cells (Buzsáki et al., 1983; Leung, 1984; cf. Lopes da Silva et al., 1990). In contrast to SPW, theta activity in the hippocampus and adjacent EC is critically dependent on medial septal neurons (Petsche et al., 1962; Mitchell et al., 1982; Stewart and Fox, 1989; Lee et al., 1994), which provide a prominent source of rhythmic afferent input.

As described, much more is known about the relation of neural activity throughout the brain to the theta rhythm as compared to SPW. Accordingly, the primary focus of the present study was to examine the activity of neurons within medial retrohippocampal regions - the subiculum, presubiculum, parasubiculum, and medial EC-during the SPW states (awake immobility, slow wave sleep), and additionally to compare these patterns to activity observed during periods of theta (locomotor activity, REM sleep). We found that neurons in the deep (VVI), but not superficial (II-III), layers of retrohippocampal structures discharge together with hippocampal pyramidal cells during SPW. In contrast, cells in the superficial, but not deep, layers fire phase-related to hippocampal theta waves.

\section{Materials and Methods}

Animals and surgery. Twenty-six adult Sprague-Dawley rats were used in the following experiments. For surgery, rats were anesthetized with a ketamine cocktail $(4 \mathrm{ml} / \mathrm{kg}$ ) consisting of $25 \mathrm{mg} / \mathrm{ml}$ ketamine, $1.3 \mathrm{mg} /$ $\mathrm{ml}$ xylazine, and $0.25 \mathrm{mg} / \mathrm{ml}$ acepromazine. Following a midline scalp incision, twin burr holes were drilled in the skull over the hippocampus. Two sets of four $50 \mu \mathrm{m}$ tungsten wires were positioned into the dorsal hippocampus (AP -3.0 from bregma, ML 2.5, DV 2-3.00 from the skull, according to Paxinos and Watson, 1986). One set was chronically fixed, while the other was attached to movable machine screws. The latter allowed for optimal, postsurgical positioning of electrodes in the dorsal hippocampus. A threaded microdrive mount was positioned over either the left or right retrohippocampal area oriented $10^{\circ}$ from vertical (AP -8.0, ML 3-4.0). This mount allowed for the passage of a 0.5-3.0 M\& tungsten microelectrode through the medial retrohippocampal region using a movable microdrive unit. A pair of $150 \mu \mathrm{m}$ wires were also positioned in the angular bundle for stimulation of the perforant path (AP 7.2, ML 4.2, DV 4.0). Two stainless steel watch screws driven into the bone above the cerebellum served as an indifferent and ground electrodes. Two additional support screws were positioned anterior to bregma, and the entire ensemble was secured to the skull with dental acrylic. All electrodes, indifferent, ground, and stimulating, were attached to male pins that were secured in a rectangular $3 \times 4$ pin array and secured with dental acrylic.

Recording. Bioelectrical activity was recorded in freely behaving rats. The animal's headstage (male pins) was directly connected to 16 MOSFET-input operational amplifiers mounted in a female connector. This high-input-impedance headstage serves to eliminate cable movement artifacts (Buzsáki, 1989). An attached cable fed into a rotating swivel allowed for the free rotation of the recording cable and rodent. An amplifier system (Grass) and an analog-to-digital hard/software system (RC Electronics) run on a PC computer allowed for direct visualization and storage of electrical activity. Wideband signals $(1 \mathrm{~Hz}$ to $5 \mathrm{kHz})$ were sampled at $10 \mathrm{kHz}(100 \mu \mathrm{sec})$ and stored on optical disks.

Following optimization of hippocampal microelectrodes for detection of SPW, the tungsten microelectrode was lowered through retrohippocampal structures via the microdrive. Discriminable units were recorded during both SPW (awake immobility) and theta states (locomotor activity and paradoxical sleep). Following isolation of a unit, 100-200 epochs $(400 \mathrm{msec})$ pretriggered by the occurrence of an SPW were recorded. When possible (depending upon the stability of unit recording) additional continuous epochs $(30-60 \mathrm{sec})$ were recorded during both SPW (awake immobility) and theta (locomotion or REM sleep). Following completion of a single pass of the microelectrode, rats were anesthetized with pentobarbital and perfused with the electrode in situ. A single pass was utilized to optimize the location of recording sites along the retrohippocampal pathway. In several instances, after data collection from a well-isolated unit, the rat was sacrificed with the electrode left at that position. Serial histological sections (see below) then unmistakenly revealed the recorded layer. In other instances, the data wcrc collected throughout the track and the laminar distribution of the recorded units was calculated by the number of turns of the microdrive and the histologically verified tip of the microelectrode (e.g., Fig. $4 A, B$ ).

Data processing and analysis. Unit activity and field potentials were separated by digital filtering (unit, band pass $0.5-5 \mathrm{kHz}$; field, low pass $50 \mathrm{~Hz}$ ) and analyzed off line. Isolation of single units was defined by the refractoriness of discharges ( $\geq 1 \mathrm{msec}$ suppression in the autocorrelograms). Unit activity that failed to show refractoriness (with interspike intervals $<1 \mathrm{msec}$ ) was considered multiunit. Typically, a wellisolated unit as well as multiunit activity could be recorded at a single electrode site (see Fig. 1).

In order to assess alterations in unit activity during SPW, crosscorrelograms (perievent histograms, $1.6 \mathrm{msec}$ resolution) between single-unit activity and a threshold discrimination of the occurrence of an SPW were used. Data were then cumulated over nine sequential 40 msec bins from +180 to -180 msec prior to the SPW. The SPW epoch was defined as that period from -20 to $+20 \mathrm{msec}$ from zero (the threshold discrimination of the SPW). Each $40 \mathrm{msec}$ bin was then compared to baseline using Dunnett $t$ tests with $p$ set at $\leq 0.01$ in order to define significant alterations in unit activity during SPW epochs. In order to assess theta-related alterations in unit activity, cross-correlograms between discriminated unit activity and a threshold discrimination of the positive phase of theta were utilized. Theta periods during locomotion or REM sleep of a minimum $10-30 \mathrm{sec}$ were used for such assessments.

Histology. Tissue was processed using either thionin stain or a modified silver method that allows for direct visualization of damaged neurons (Gallyas et al., 1990). The latter technique allowed for more direct visualization, and thus localization, of ncurons at the electrode tip. Briefly, following completion of the experiments the rats were deeply 
Figure 1. SPW and associated neuronal events in the hippocampus and entorhinal cortex $(E C)$. $A$, SPW events in the CAl region: 1 , the positivity observed in stratum oriens (digitally filtered off line, low pass $50 \mathrm{~Hz}$ ); 2, the high-frequency oscillation (ripple) observed in stratum pyramidale (band pass $100-400 \mathrm{~Hz}$ ); and 3 , the sharp negativity or SPW recorded in stratum radiatum (low pass $50 \mathrm{~Hz}$ ). $B$, High-bandpass-filtered $(0.5-5 \mathrm{kHz})$ recording from the pyramidal cell layer (same as ripple trace) illustrating single- $\left({ }^{*}\right)$ and multiunit activity. Perievent histograms were generated from over 100 successive SPWs for single- (black) and multiunit (gray) CA1 neurons (as illustrated in trace). Firing rates have been corrected for number of epochs in all perievent histograms. $C$, SPW-concurrent event in the EC and radiatum ( $C A 1 \mathrm{rad}$; at same site as shown in A). Asterisks indicate discriminated single units for this epoch. Single-unit activity was determined by spike autocorrellograms with $>1 \mathrm{msec}$ interval between successive spikes (see inset in $C$ ). Perievent histograms (bottom) of EC neurons are illustrated above over 100 SPW epochs. Note similarity between histogram of single-unit (black) and multiunit (gray) activity.
A

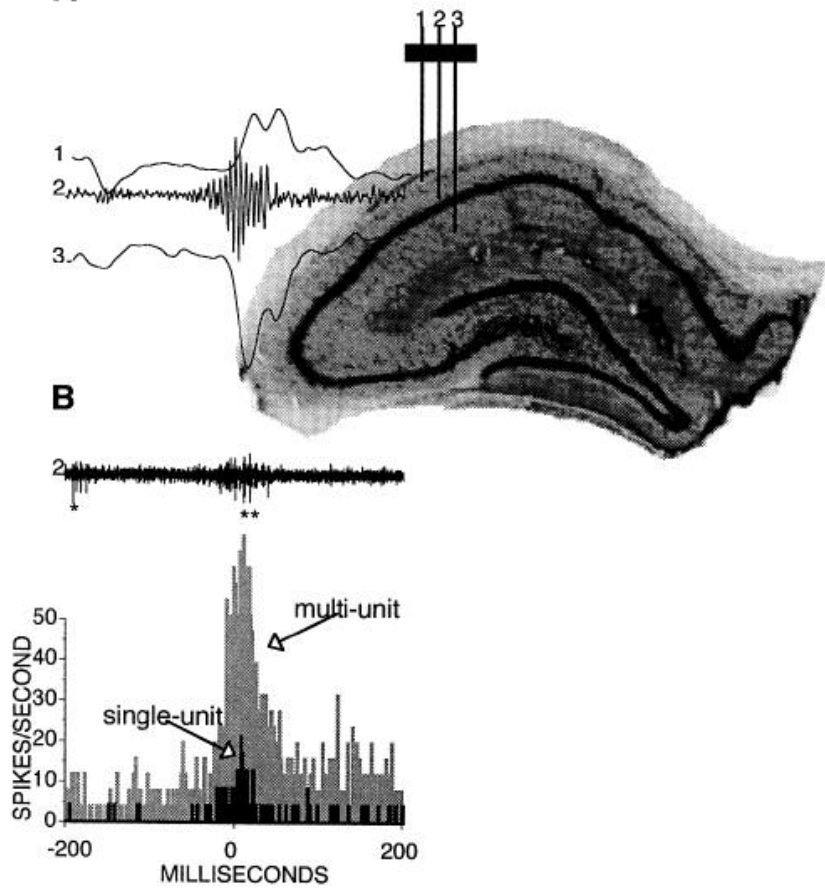

C

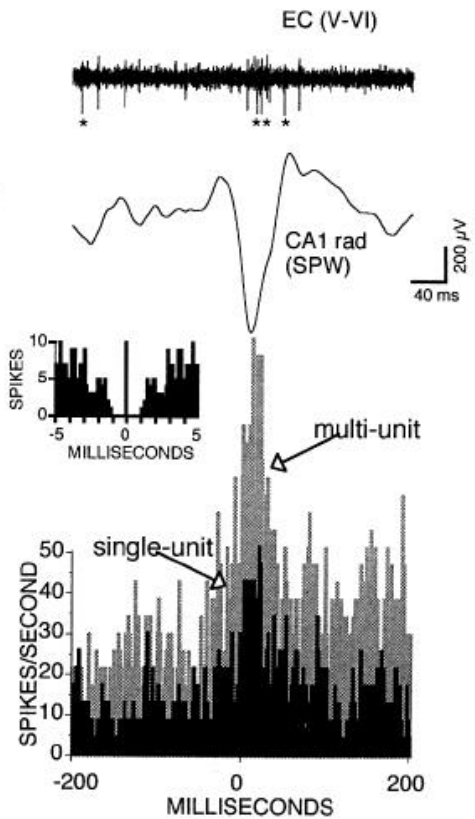

anesthetized and perfused through the heart first with cacodylate-buffered saline $(\mathrm{pH} 7.5)$ followed by a cacodylate-buffered fixative containing $4 \%$ paraformaldehyde and $5.9 \%$ calcium chloride $(\mathrm{pH} 7.5)$. Brains were left in situ for $24 \mathrm{hr}$, removed, and then postfixed in the same solution for 1 week. The brains were sectioned on a vibrotome at 80 $\mu \mathrm{m}$. The sections were stained with the Gallyas silver method (Gallyas et al., 1990). Briefly, the sections were dehydrated with propanol and placed in an esterifying solution ( $98 \%$ propanol, $1.2 \%$ sulfuric acid) at $56^{\circ} \mathrm{C}$ for $16 \mathrm{hr}$. After rehydration and sectioning they were processed according to the following procedure: (1) pretreatment in $8 \%$ acetic acid for $10 \mathrm{~min}$, (2) washed in water for $1 \mathrm{~min},(3)$ physical development with tungstosilicic acid for approximately $10 \mathrm{~min}$, and (4) wash in $1 \%$ acetic acid. Finally, the sections were dehydrated, mounted on slides, and coverslipped.

\section{Results}

\section{Hippocampal SPW}

In accord with previous findings (Buzsáki et al., 1983; Suzuki and Smith, 1987), we observed sharp negative field potentials in the CA1 stratum radiatum (Fig. 1) during non-theta states (awake immobility). These field potentials were phase-reversed above stratum pyramidale; thus, a positive deflection can be observed in stratum oriens. A prominent high-frequency oscillation at approximately $200 \mathrm{~Hz}$ (ripple) was observed as electrodes traversed near the pyramidal cell layer coincident with the SPW. During SPW, CA1 neurons participate in population bursts (Fig. $1 B$ ), during which unit activity can become entrained, or phase-locked, to the high-frequency ripple (Buzsáki et al., 1992).

\section{Relation of retrohippocampal neurons to SPW}

While simultaneously recording SPW in stratum radiatum or oriens, and often ripples and CA1 population bursts in the pyramidal layer, a single microelectrode was lowered via the mi- crodrive through the retrohippocampal region. The discharge properties of 56 putative single neurons within retrohippocampal structures and 18 within the overlying neocortex were assessed in relation to hippocampal SPW. Additionally, multipleunit activity was assessed at 122 sites in 26 rats.

Our primary finding was a significant SPW-related increase in the activity of retrohippocampal neurons throughout the subiculum ( 9 of 13), and deep layers (V-VI) of the presubiculum (4 of 4), parasubiculum (4 of 4), and entorhinal cortex (9 of 11) (Figs. $1 C, 2,3)$. Of 19 deep layer retrohippocampal cortical neurons, 18 exhibited significant changes during the SPW epoch. Seventeen (of these 19) exhibited a significant increase in activity, one exhibited no change, and one exhibited a significant decrease during the SPW epoch. Previous findings have demonstrated that a small population $(<1 \%)$ of physiologically identified hippocampal interneurons also exhibit significant decreases during SPW (Urioste et al., 1992).

As illustrated in Figures 1-3, single neurons demonstrated a two- to fivefold increase in firing during the SPW epoch. The majority of SPW-related units showed a significant increase in activity during the SPW epoch $(-20$ to $+20 \mathrm{msec}$ from a threshold discrimination of the SPW), during either the rising or falling phase of the SPW potential. Typically, as electrodes passed from strongly SPW-related recording sites in the deeper layers, units were observed that had diminished relation to the SPW (see Fig. 5) and/or exhibited a significant increase in activity in the period after the SPW epoch. Of 12 neurons recorded within layers IV-III, four that were located in the presubiculum ( $n=$ 2) and caudal entorhinal $(n=2)$ exhibited a significant increase in the periods +20 to $+180 \mathrm{msec}$ following the SPW without any altered activity during the SPW epoch (see Fig. 3, intermediate retrohippocampal graph). These neurons were located 
A) DORSAL PRESUBICULUM
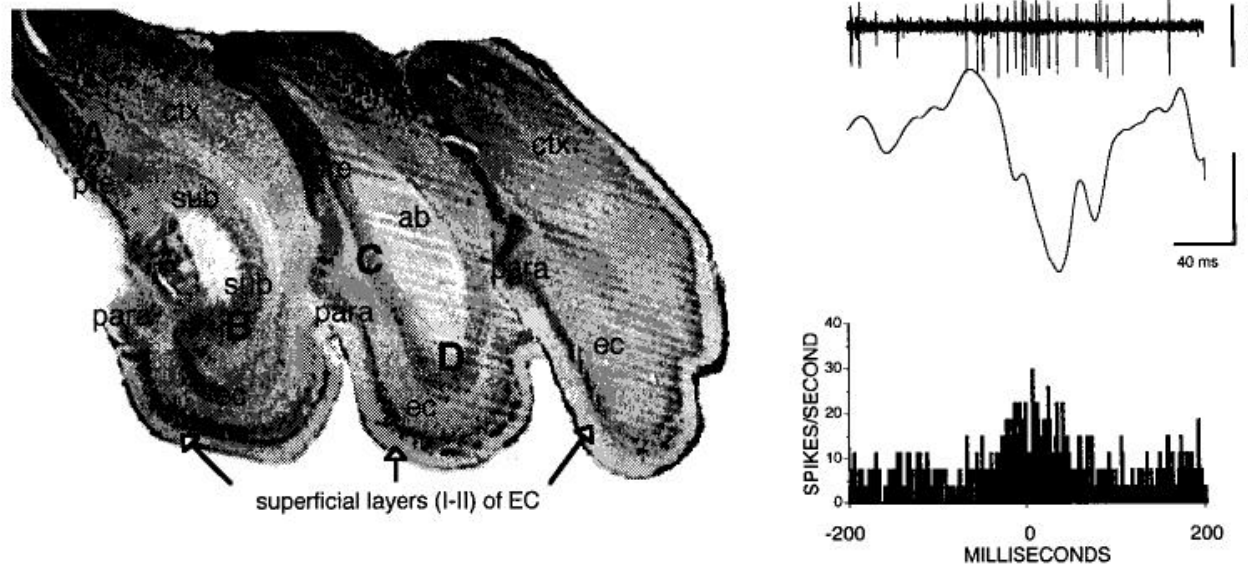

B) VENTRAL SUBICULUM

C) PARASUBICULUM
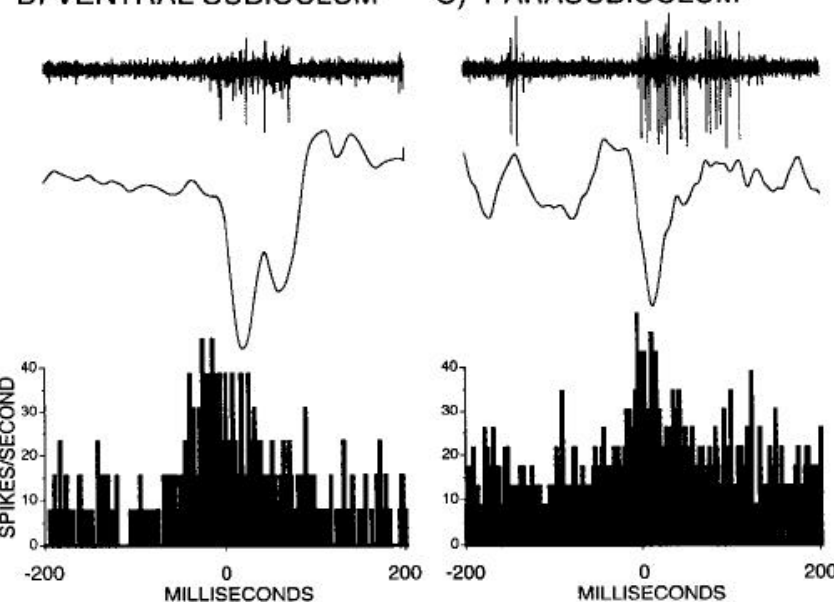

D) ENTORHINAL CORTEX
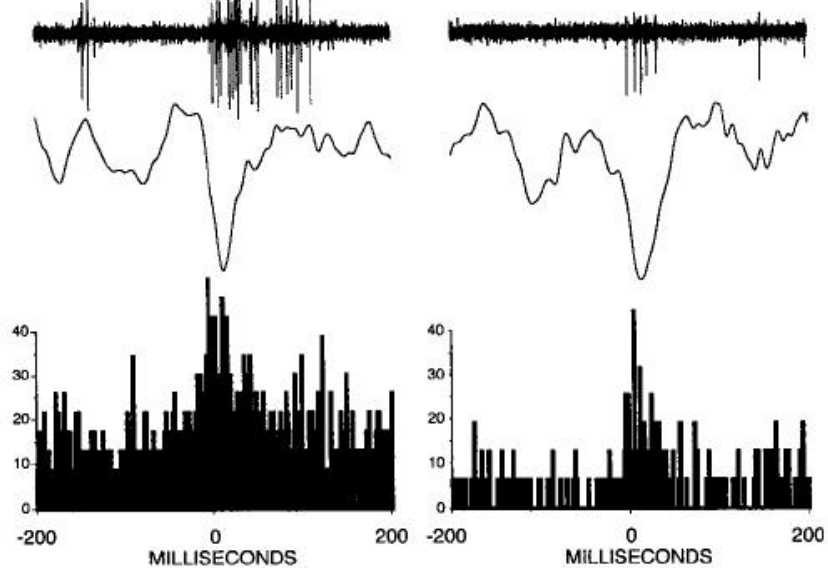

Figure 2. Illustration of retrohippocampal structures in coronal sections where neuronal activity was sampled during hippocampal SPW. The majority of units were sampled from the medial EC. Locations $A-D$ correspond to recording sites where neurons exhibited a SPW related increase in activity. Panels $A-D$ illustrate unit activity (top trace) in respective regions concurrent with hippocampal SPW (bottom trace) over single $400 \mathrm{msec}$ epochs. Perievent histograms illustrate cumulative activity of illustrated neurons over $>100$ SPW epochs. $a b$, angular bundle; $c t x$, neocortex; pre, presubiculum; para, parasubiculum; $e c$, entorhinal cortex. ventral to typical SPW-related neurons. The remaining neurons ventral to the SPW-related deep layer neurons, which includes layer IV and the broader expanse of layer III, exhibited no relation to the SPW. With the present methods, we could not clearly distinguish between layer III and IV neurons. Neurons recorded at the end of the electrode track $(N=12)$ could be defined as layer II cells (Fig. 4). No SPW-related alteration of activity was observed in any of these neurons (see Figs. 3-6). Neurons recorded in the overlying neocortex $(N=18)$ did not display any reliable relationship to the SPW (Figs. 3, 5, 6).

In contrast to the SPW patterns, deep layer neurons appeared indifferent to prominent theta potentials recorded within the deep layers of the EC and hippocampus (Fig. 5). Theta potentials were in phase with CA1 theta in all EC layers dorsal to layer II during movement and REM sleep. The rhythmicity in unit discharge, however, was only observed in the superficial layers (Figs. 4, 6). The discharge pattern of neurons recorded along the medial and ventral walls (superficial layer II) of the presubiculum and entorhinal cortex were often theta modulated (seven of eight tested), while none of these units were correlated to SPW events ( $N=12$; see Figs. 3-6). To summarize, we have not observed a significant alteration, excitation or inhibition, in the firing of any superficial layer neuron within the retrohippocampal cortex during SPW.

Analysis of multiunit data was in almost all cases consistent with analyses of defined single units (see Figs. 1,6) with respect to SPW and theta relationships. In the rare case, multiunit activity in the superficial layer (II) in relation to theta, and for sites in the intermediate layers (III-IV) that fired in periods after the SPW, no alteration was observed for multiunit analyses where isolated analysis of single units exhibited a clear theta modulation or increase in firing in relation to SPW. Analysis of multiunit data at deep layer sites, where no single unit could be defined, supported the SPW-related activity of neurons within this lamina. Multiunit analysis of superficial layer neurons also supported the relationship of neurons in this lamina to theta and their indifference to SPW.

\section{Discussion}

Our findings demonstrate that neurons within the deep layers of retrohippocampal structures significantly increase their discharge rate during hippocampal SPW. Thus, the synchronous activation of CA3, CA1, and subicular neurons during SPW is a characteristic feature of retrohippocampal output pathways that include the deep layer (V-VI) neurons of the presubiculum, parasubiculum, and EC. The discharge pattern of deep layer neurons appears largely unrelated to hippocampal or entorhinal theta, in agreement with previous observations (Alonso and Garcia-Austt, 1987b; see also Quirk et al., 1992). In contrast, superficial neurons (layers II-III), which have been shown to be phase-related to theta oscillations (Mitchell and Ranck, 1980; Alonso and Garcia-Austt, 1987b; Stewart et al., 1992; present 

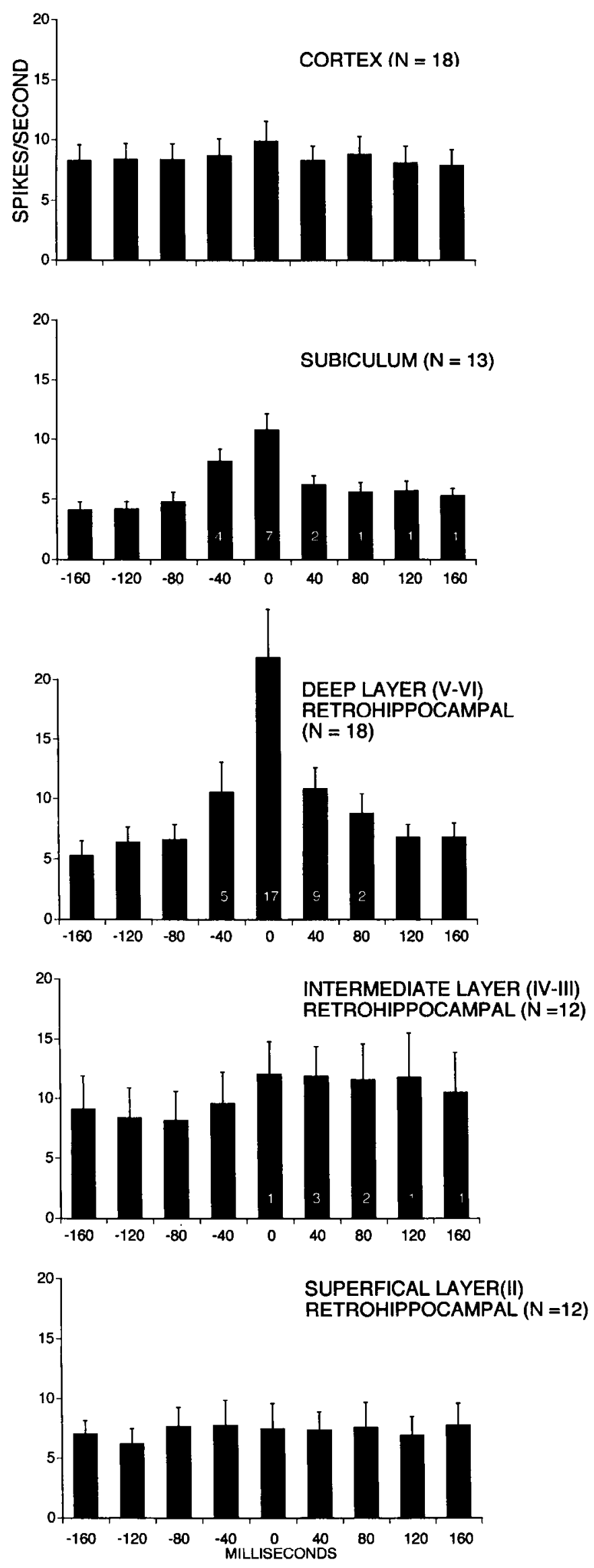

findings), are indifferent to the population bursting occurring within the deep layers during SPW.

\section{Laminar differences define relation of retrohippocampal neurons to SPW and theta}

These findings indicate distinct laminar differences in the discharge patterns of retrohippocampal neurons during SPW and theta. Given the anatomical and physiological connectivity of CA3-CA1-subiculum-presubiculum-parasubiculum and EC (Köhler, 1985a,b; Finch et al., 1986, 1988; Witter et al., 1989; Lopes da Silva et al., 1990; Van Groen and Wyss, 1990; Lingenhohl and Finch, 1991), it may be expected that the bursting activity of $\mathrm{CA} 3$ and $\mathrm{CA} 1$ is associated with an increased excitability of these retrohippocampal neurons. The indifference of more superficial neurons (layers II-III) to population bursts within the deep layers, however, is a striking aspect of the present findings.

Several studies have demonstrated the responsiveness of deep and superficial layer EC neurons following repetitive hippocampal stimulation (Deadwyler et al., 1975; Finch et al., 1986, 1988; Jones and Heinemann, 1988; Jones and Lambert, 1990; Paré et al., 1992). However, recording of physiological activity within this circuit suggests that activation of superficial layer EC neurons is not a typical consequence of population activity within CA1, subicular, or deep layer EC neurons. Since excitatory connections between layer $\mathrm{V}$ and layer II/III neurons have been demonstrated (Jones, 1993; cf. Heinemann et al., 1993), the lack of recruitment of superficial layer neurons into the SPW burst suggests that these excitatory inputs are relatively weak and/or are counteracted by a stronger inhibitory influence. Köhler $(1985 a, b)$ described widespread efferent projections from the deep layers of the medial EC to all more superficially located layers in the medial and lateral EC as well as to the pre- and parasubiculum. Some of this projection was thought to derive from an interneuron population in layer VI, as well as from the more prominent pyramidal cell population (Köhler, 1985a,b). Based on our findings, we suggest that the excitatory connectivity of the deep to superficial layer is considerably less than widely believed or that much of the projection mediates direct and/or feedforward inhibition. Such a hypothetical feedforward mechanism could provide for a selective communication from deep to superficial layer neurons (Fig. 7). The substrate of such

\footnotetext{
Figure 3. Group averages of single units recorded from the overlying neocortex (primarily occipital cortex), subiculum, and retrohippocampal structures. Neurons within the presubiculum, parasubiculum, and EC have been collapsed because they had similar relationships with SPWs. For each neuron, each $40 \mathrm{msec}$ bin was compared to a baseline period ( -180 to $-140 \mathrm{msec}$ from threshold discrimination of the SPW). The number of neurons with significant alterations in firing rate $(p<$ $0.01)$ during each subsequent bin $(40 \mathrm{msec}$ period) is indicated at the base of each bar (i.e., 17 of 18 deep layer retrohippocampal neurons exhibited significant increase in firing rate during the peak of the SPW; one deep layer neuron that was inhibited during the SPW was not included in the group average). Significant alterations were determined by Dunnett $t$ tests between baseline and successive $40 \mathrm{msec}$ bins with $p$ set at $<0.01$. Note that most SPW-associated neurons exhibited significant increases in activity for more than one $40 \mathrm{msec}$ bin; thus, 9 of 17 deep layer neurons also exhibiled a significant increase in the subsequent $40 \mathrm{msec}$ period. A few intermediate layer (IV-III) neurons exhibited altered firing rates in the periods after the SPW epoch without any significant alteration prior and during the peak of the SPW. Note that neocortical and superficial layer neurons did not increase their firing rates in relation to SPW.
} 
A

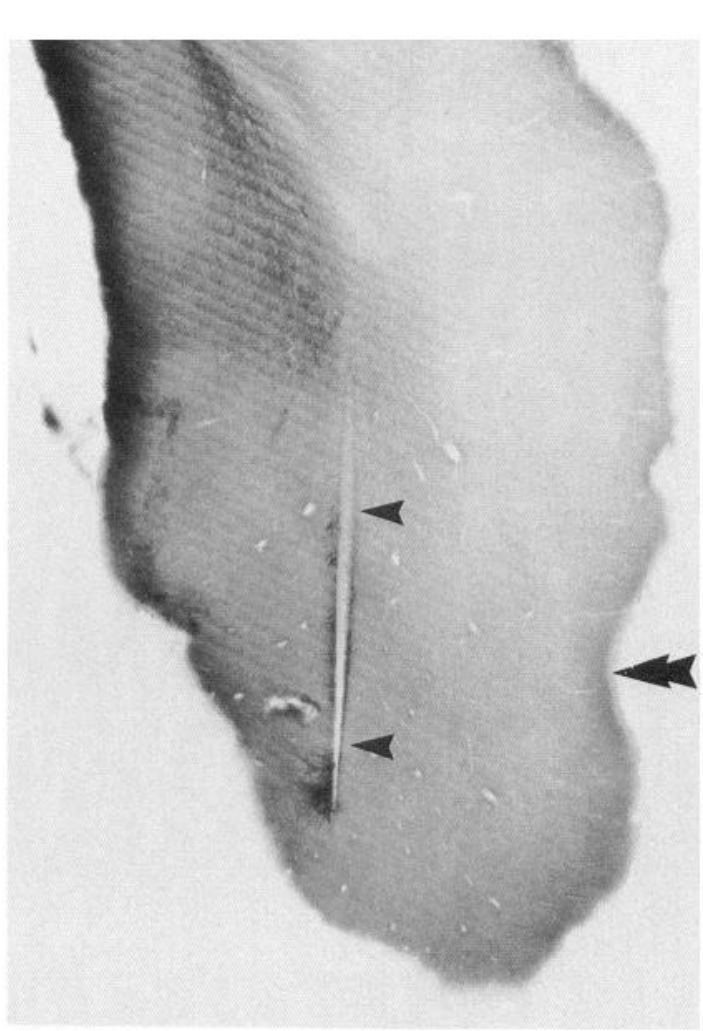

B

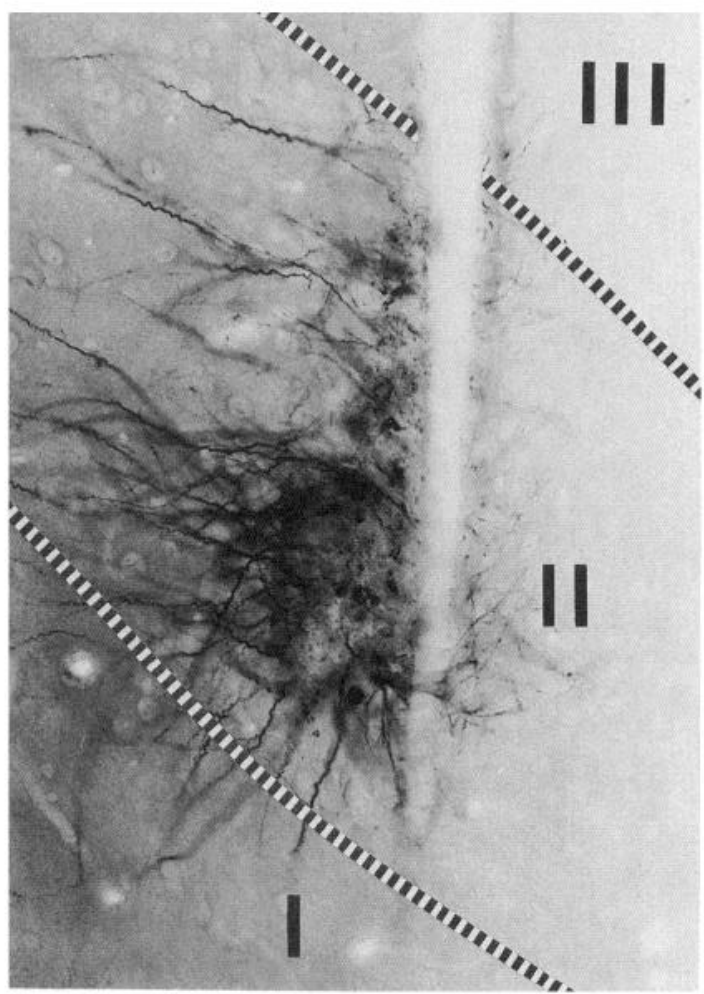

C
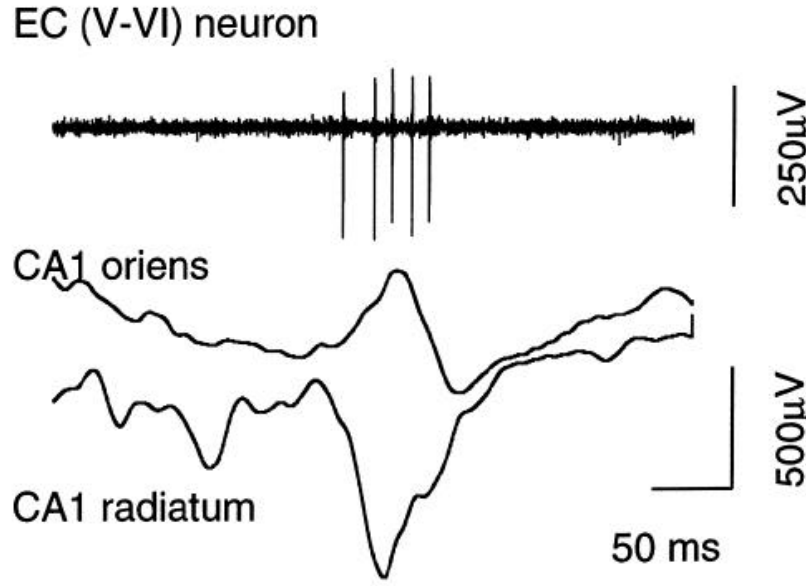

공

D

EC (II) neuron

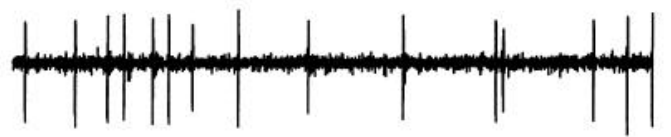

옹

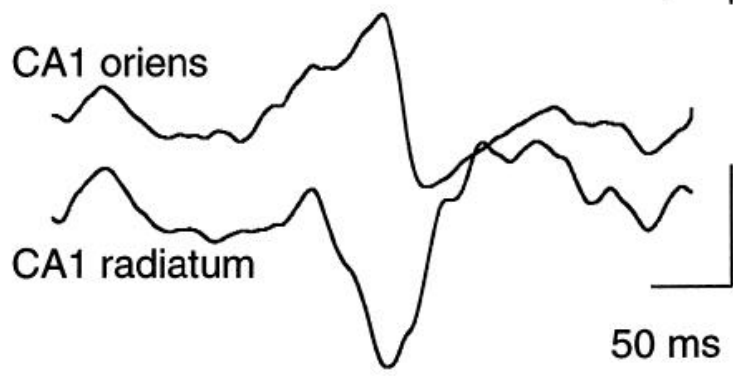

흥

E EC (II) neuron

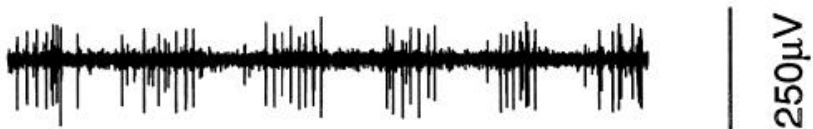
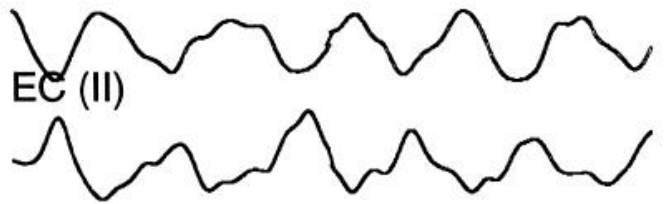

CA1 radiatum

\section{言} .

.



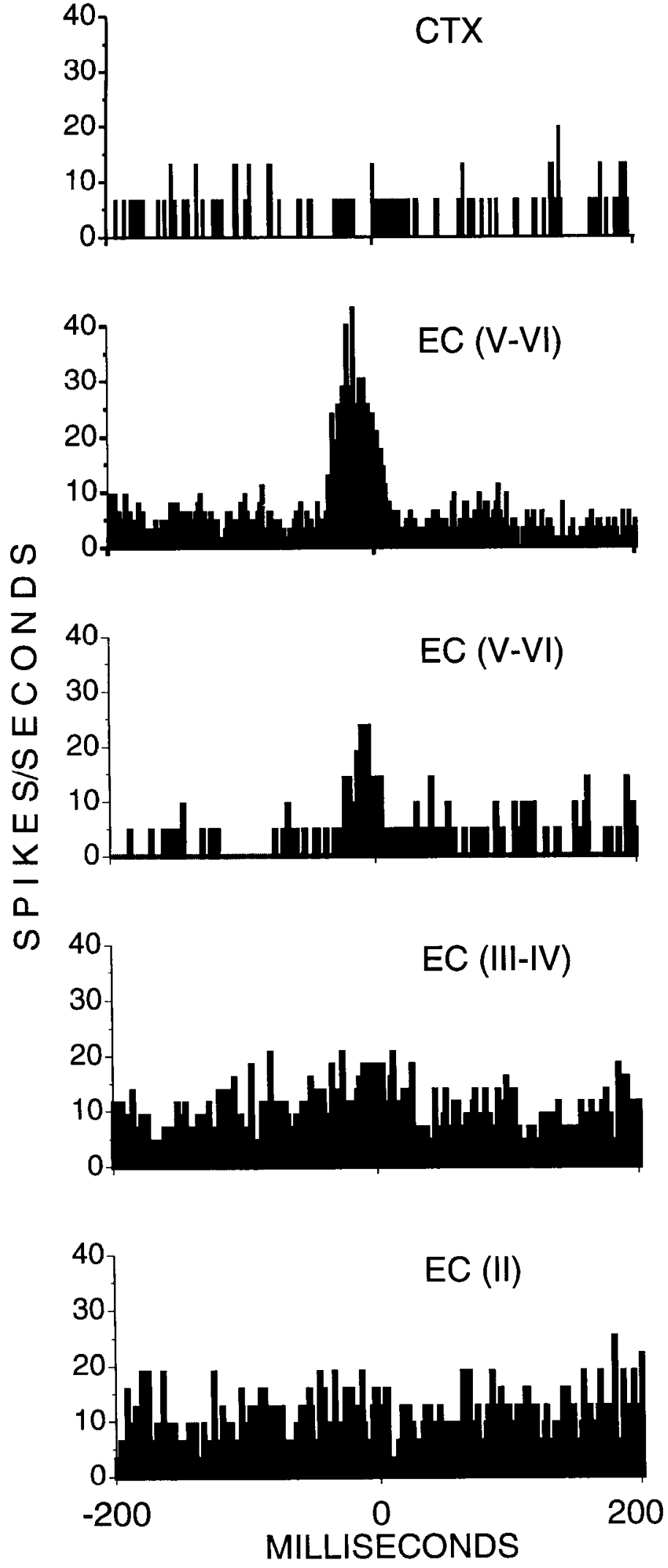

Figure 5. Neurons recorded in a single electrode pass through the EC. Perievent histograms indicate the relation of neocortical, layer V-VI, layer III-IV, and layer II EC neurons. Within a single electrode pass, we observed neurons that exhibited a dramatic increase in firing in relation to SPW $[E C(V \cdot V I)]$. Neurons located just ventrally exhibited a decreasing relation to the SPW. As electrodes traversed the more a coupled excitatory and feedforward inhibitory path from deep to more superficial layers is compatible with the available physiological findings (Lingenhohl and Finch, 1991; present results), even though it is not directly supported by anatomical evidence. We are unaware of any data demonstrating the innervation of inhibitory interneurons by deep layer cells or of a direct inhibitory projection from the deep layer. The widespread, and numerically larger, distribution of GABAergic interneurons and GAD-immunoreactive terminals within the superficial layer as compared to the deep layer (Köhler et al., 1985), as well as the strong inhibitory responses in superficial entorhinal neurons following afferent stimulation (Lingenhohl and Finch, 1991), may suggest a powerful inhibitory network that suppresses the influence of deep layer excitatory input to superficial neurons. Further anatomical studies will be necessary to define the intralaminar connectivity of the EC.

A number of findings have indicated the heterogeneity of neuronal types within and between distinct lamina within the neocortex. Considerable evidence demonstrates that within the deep layers (V-VI) of several neocortical areas there exists a significant population of burst-generating neurons (Connors, 1984; Chagnac-Amitai et al., 1990). These neurons, once released from subcortical and intracortical input, are thought to contribute to synchronizing cortical slow wave activity (cf. Wang and McCormick, 1993). Neurons with similar electrophysiological properties (intrinsic bursting currents) have been described in the deep layers of the EC (cf. Heinemann et al., 1993) and subiculum (Stewart and Wong, 1993) and are characteristic of CA3 pyramidal cells (Traub and Miles, 1991). In contrast, Jones and colleagues (Jones and Heinemann, 1988; Jones and Lambert, 1990; Jones, 1993) have not observed such neurons within the superficial layers (II) of the EC. Rather, within layer II of the EC the predominant stellate cells possess rhythmic subthreshold membrane oscillations tuned to produce activity at the theta frequency (Alonso and Llinás, 1989; Klink and Alonso, 1993).

It is important to recognize that various cortical areas and specific lamina vary with regards to the number of intrinsically bursting neurons and thus as well as to the number of regularspiking cells that can be driven to fire concurrently during synchronized bursts. The endogenous bursting property of deep layer retrohippocampal neurons will facilitate synchronized bursts driven by the concurrently discharging hippocampal cells during SPW events. This interpretation is compatible with the view that synchronized population activity is dependent upon the intrinsic membrane properties, the local network circuitry, and the influence (or absence) of extrinsic inputs (Traub and Wong, 1982; Buzsáki et al., 1983; Steriadé and Buzsáki, 1990; Wang and McCormick, 1993).

Synchronization of hippocampal/retrohippocampal output pathways during SPW: a candidate mechanism for memory trace transfer

The temporally coordinated activities of neurons within spatially distributed networks are important functional units within the nervous system (Hebb, 1949). Rhythmic field potentials, which reflect the pattern of afferent inputs impinging upon neu-

superficial layers (II-III), neurons were indifferent to the population bursting occurring within the deep layers. 


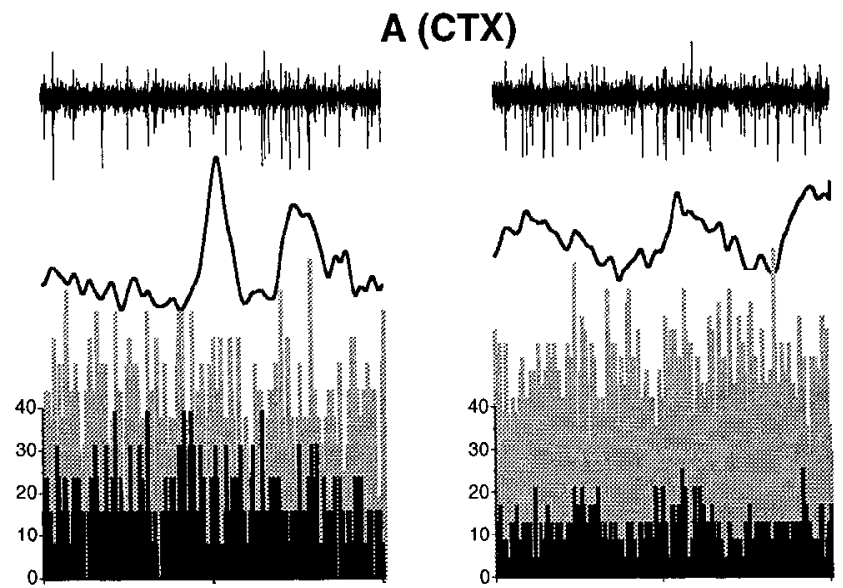

\section{B (EC V-VI)}
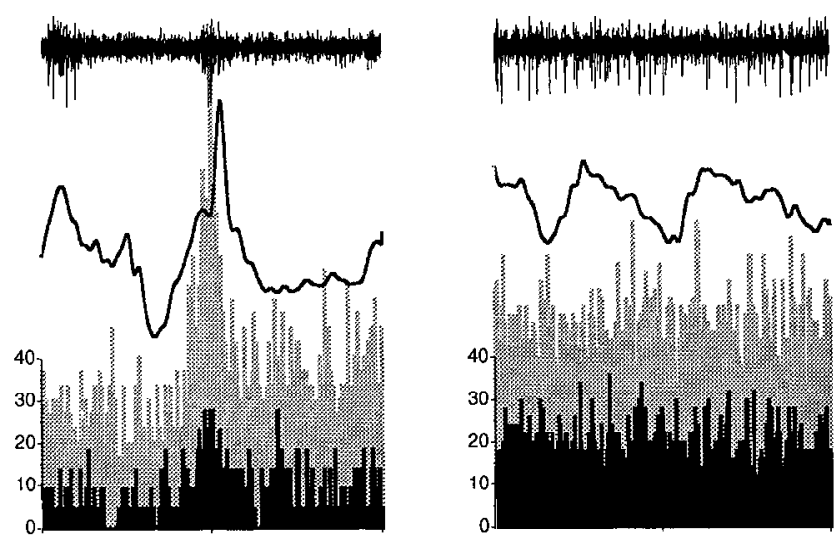

C (EC II)
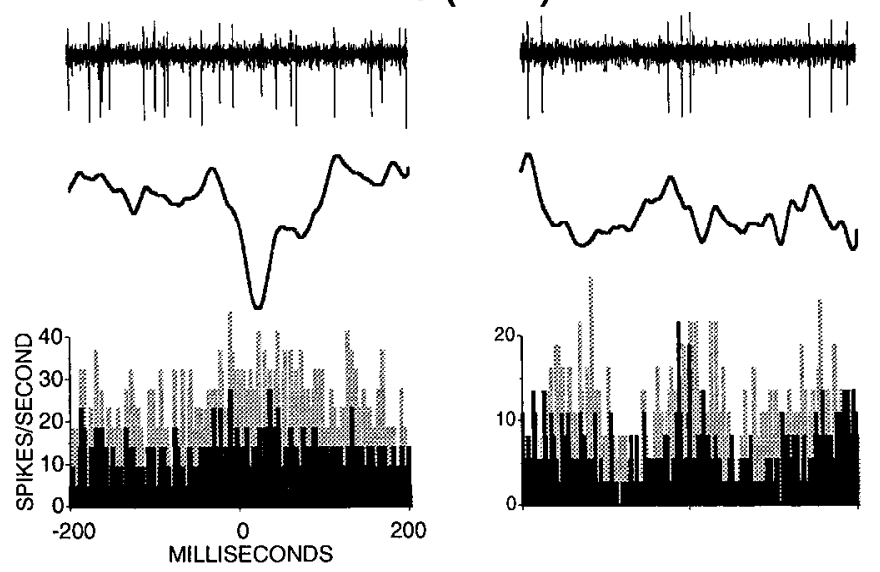

Figure 6. Laminar distinction in the relationship of EC neurons to SPW versus theta oscillations in three neurons located in the neocortex $(A)$, the deep layers $(\mathrm{V}-\mathrm{VI})$ of the $\mathrm{EC}(B)$, and layer II of the EC $(C)$. Note recording site was at same location for each EEG state, SPW (left) and theta (right). Top trace shows $400 \mathrm{msec}$ of single and multiunit activity. Second trace shows concurrent $400 \mathrm{msec}$ trace of hippocampal field potentials illustrating positive SPW in stratum oriens or negative SPW in stratum radiatum (left side of pairs) or hippocampal theta waves (right side of pairs). Gray perievent histograms are for multiunit activity, while black perievent histograms are for single units as defined by refractoriness of discharges (see Materials and Methods and Fig. 1 for details). Note the absence of relationship between neocortical neuron and SPW or theta $(A) . B$ and $C$, EC layer V-VI neurons exhibited increased activity during SPW but were relatively unrelated to theta oscillations $(B)$, while layer II neuron was theta modulated and indifferent to SPW $(C)$.

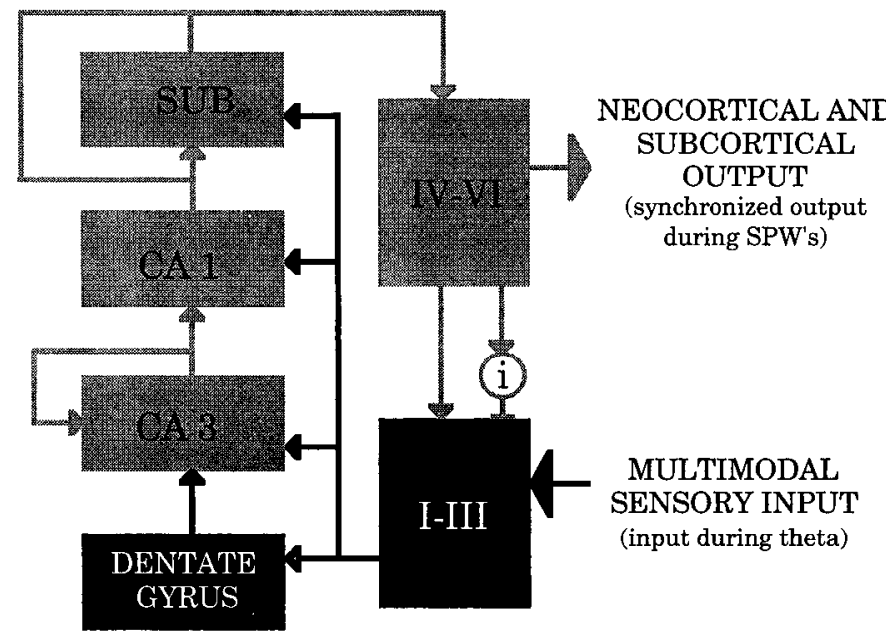

Figure 7. Schematic diagram of hippocampal-retrohippocampal connectivity as well as the temporal discontinuity in the activity of the network. The activity of neurons within this network is organized around behaviorally induced alterations in hippocampal EEG patterns. During exploration, hippocampal and entorhinal EEG exhibits pronounced theta oscillations to which hippocampal neurons are entrained. During theta, neurons within layers II-III of the EC process and relay multimodal information into hippocampal circuits (pathway outlined in black). During this period, the output neurons of the hippocampus (CA3, CA1, and subiculum) are actively suppressed by subcortical inputs that produce theta. On this silent background, only a few neurons, carrying highly specific information (e.g., spatial position of the animal), discharge. In contrast, when exploration ceases, and the animal sits immobile or engages in consummatory behavior, CA3, CA1, subicular, and deep layer (V-VI) retrohippocampal neurons participate in a synchronized population burst (pathway outlined in gray). The concerted discharge of deep layer cells of the EC, in turn, can exert a strong depolarization effect on widespread neocortical targets. Neurons in layers I-III of the EC do not participate in these SPW events. The spread of activation from layers V-VI to layers I-III is postulated to be prevented by a parallel feedforward inhibitory circuit $(i)$.

ronal elements, serve as temporal frameworks for synchronizing neural activity (Buzsáki et al., 1983, 1994; Churchland and Sejnowski, 1992; Gray, 1993; Steriade et al., 1993). Elaboration of the neuronal types and discharge patterns during endogenous potentials serves as building blocks for assessing the functional processes subserved by network activity. Theta oscillations, for example, involve coordinated neuronal activity over many brain regions and are presumably related to the synchronization of neurons subserving the representation of ongoing sensory information. Bringing neurons together in time is the function subserved by endogenous synchronizing potentials within the brain (Freeman, 1975; Buzsáki et al., 1983, 1994; Eckhorn and Obermueller, 1993; Gray, 1993; Steriade et al., 1993). The temporal synchrony of neurons within the hippocampal-retrohippocampal network during the time window of the SPW provides a potent means of enhancing their impact on common postsynaptic targets. The temporal synchrony of population discharges within this distributed network is further synchronized by the occurrence of high-frequency oscillations occurring near the pyramidal cell layer during each SPW cvent. Thus, the discharge of CAl neurons during the SPW is phase-related to a $200 \mathrm{~Hz}$ field oscillation within stratum pyramidal (Buzsáki et al., 1992). Our recent findings indicate that the discharge of deep layer entorhinal neurons is also synchronized to a $200 \mathrm{~Hz}$ oscillation 
during SPW events (Chrobak and Buzsáki, 1994). If convergent activation of neurons is related to potentiating synaptic efficacy (Bliss and Lomo, 1973; Gustafsson and Wigström, 1990), then the mechanisms that produce the convergent activity of CA3, CA1, subicular, and deep layer presubicular, parasubicular, and EC neurons during SPW-related high-frequency discharges may be a potent, endogenous, means for modifying the synaptic connectivity of this network. We suggest that SPW-associated population bursts represent the concurrent activation of distinct subsets of network neurons and that long-term alterations in synaptic efficacy are the physiological role of this organized network burst.

The hippocampal-entorhinal network is an important substrate in the formation of memories. It is believed that multimodal sensory information from neocortical sites converges on the superficial layers of the EC (Amaral, 1987; Van Hoesen et al., 1991), where it is processed and relayed into hippocampal circuits (see Fig. 7). Following hippocampal processing, which presumably involves the integration of highly processed sensory input with subcortical input, information is returned to the deep layers of the $\mathrm{EC}$, from which it can be communicated to the entire cortical mantle (Van Hoesen and Pandya, 1975; Swanson and Köhler, 1986). The role of hippocampal circuits, where multimodal sensory representations are integrated with subcortical inputs, may involve determinations of the importance or relevance of incoming sensory information (Van Hoesen et al., 1991; Chrobak et al., 1994). Hippocampal processing may then subsequently influence the degree and/or nature of synaptic modification made within hippocampal-retrohippocampal and neocortical circuits.

Critically, insult to this network in human neurologic disorders (e.g., Alzheimer's dementia) or following experimental manipulation in other animals induces memory dysfunction (Becker et al., 1980; Hyman et al., 1984; Van Hoesen et al., 1991; Cho et al., 1993; Chrobak et al., 1994). This network appears to play a role in the initial stages of memory formation (Cho et al., 1993; see Squire, 1992, for review). The time frame of this system's involvement in the process can be quite protracted. Over a period of minutes, hours, to months, memories become stored in presumably neocortical targets that are less vulnerable to postacquisition amnestic treatments. Dual-stage models of memory formation that posit an initial encoding process followed by a subsequent consolidation process (Hebb, 1949; Gold and McGaugh, 1974; Buzsáki, 1989) are consistent with evidence demonstrating (1) that damage to a hippocampal network does not effect long-term memories, but severely impairs the acquisition of new memories, and (2) the susceptibility of memories to postacquisition manipulation (Gold and McGaugh, 1974; Chrobak and Napier, 1992a,b; Squire, 1992).

Consistent with a dual-stage theory, Buzsáki (1989) has proposed that information initially encoded within hippocampal circuits during theta is subsequently consolidated within intraand extrahippocampal circuits during the SPW state. Thus, multimodal sensory representations provided by retrohippocampal afferents are registered and maintained within hippocampal circuits during theta (Otto et al., 1991). Upon cessation of ongoing activity, the network shifts to consolidating recent modifications of its inputs into a more permanent form by inducing more permanent modifications of intra- and extrahippocampal network connectivity. From our findings, it appears that these complementary patterns, hippocampal theta and SPW patterns, segregate anatomically in the $\mathrm{EC}$ (Fig. 7). During exploratory activity layer II-III neurons are actively relaying information from the neocortex into the hippocampus. In contrast, during consummatory behaviors and slow wave sleep, CA3-CA1-subicular pyramidal cells and deep layer neurons of the retrohippocampal cortex are participating in organized population bursts. The patterned activation of network output during SPW is conceived as an important functional substrate of memory formation involving the consolidation of representations within intra- and extrahippocampal circuits and potentially the coordinated transfer of information out of the hippocampus to neocortical circuits. This hypothesis is consistent with generally accepted views about the time-dependent role of the hippocampal-entorhinal circuits in memory formation, yet explicitly defines distinct time frames for dynamic modifications within the network during information acquisition (during theta) as compared the long-term consolidation of these modifications in neocortical circuits (during SPW).

\section{Role of the hippocampal-entorhinal loop in epilepsy and Alzheimer's disease}

The anatomical and physiological connectivity of the EC and hippocampus indicates that information from EC is routed through hippocampal circuits and returned to the EC. The point of cntry into this loop is the convergence of multimodal sensory cortices onto the superficial cells of the EC (Van Hoesen and Pandya, 1975; cf. Lopes da Silva et al., 1990), which provides for the perforant path innervation of the hippocampus (Steward and Scoville, 1976; see Fig. 7). Hippocampal information is returned to the deep layers (V-VI) of retrohippocampal structures, primarily the $\mathrm{EC}$, from where information is transmitted back to majority of the neocortical mantle (Lopes da Silva et al., 1990; Van Groen and Wyss, 1990). The connectivity of the deep layers of the EC to the superficial layers (Lorente de No, 1934) provides for a reentrant circuit whereby self-sustained reverberant oscillations may occur (Buzsáki, 1989; Paré et al., 1992).

Importantly, this reentrant loop appears to be critical for the development of sustained epileptiform activity within the temporal lobe (Paré et al., 1992). Several studies have demonstrated that stimulation of hippocampal outputs produces excitatory as well as inhibitory potentials, and associated unit firing within both the deep and superficial layers of the EC (Finch et al., 1986 1988; Jones and Heinemann, 1988; Jones and Lambert, 1990; Heinemann et al., 1993). In contrast, our findings indicate that physiologically occurring population bursts within the deep layer EC neurons and concurrent activity of their input (CAl and subicular neurons) are not reflected in the excitation of a large number of superficial layer neurons. Surprisingly, we did not find a single superficial neuron that significantly increased its frequency during SPW associated population bursts of layer $\mathrm{V} / \mathrm{VI}$ neurons. It appears that reentrant activation of superficial layer EC neurons following the discharge of CA1 and subicular neurons is a rare event in the intact brain. Instead of reentrant activation, information would appear to be forwarded to the neocortical mantle via entorhinal outputs.

In this regard, our findings support the general suggestions of Jones and colleagues (Jones and Heinemann, 1988; Jones and Lambert, 1990; Jones, 1993) that the distinctive inhibition of superficial layer EC plays a critical role in the control of temporal lobe epilepsy. The authors have outlined distinct laminar differences in the degree of inhibitory activity that would accord with the present findings. These collective findings suggest that 
the inhibition of superficial entorhinal cortical neurons during SPW may be a critical component in the control of reverberating activity within the entorhinal $\rightarrow$ hippocampal $\rightarrow$ entorhinal loop. Thus, failure of inhibition at this critical juncture is likely to play a role in the transition of physiological network bursting to pathophysiological reverberating epileptiform activity (Paré et al., 1992; Jones, 1993).

It is also important to note that layer II of the EC and, subsequently, the deep layers are the prime targets of the neuropathological changes observed in Alzheimer's dementia (Van Hoesen et al., 1991; Braak and Braak, 1993). Given a role of glutamate in EC cell death (Mattson and Barger, 1993), it is intriguing to speculate that some perversion of the normal physiological mechanisms that limit the responsiveness of superficial layer neurons to excitatory input from the deep layer plays a role the sequelae of neuropathological changes and ensuing memory deficit observed in this disorder.

\section{References}

Alonso A, Garcia-Austt E (1987a) Neuronal sources of theta rhythm in the entorhinal cortex of the rat. I. Laminar distribution of theta field potentials. Exp Brain Res 67:493-501.

Alonso A, Garcia-Austt E (1987b) Neuronal sources of theta rhythm in the entorhinal cortex of the rat. II. Phase relations between unit discharges and theta field potentials. Exp Brain Res 67:502-509.

Alonso A, Klink R (1993) Differential electroresponsiveness of stellate and pyramidal-like cells of medial entorhinal cortex layer II. J Neurophysiol 70:128-143.

Alonso A, Llinás $\mathrm{R}$ (1989) Subthreshold $\mathrm{Na}^{+}$-dependent theta-like rhythmicity in stellate cells of entorhinal cortex layer II. Nature 342 : 175-177.

Amaral DG (1987) Memory: anatomical organization of candidate brain regions. In: Handbook of physiology, The nervous system V, Sec 1, Vol 1, pp 211-294. Bethesda, MD: American Physiological Society.

Becker JT, Walker JA, Olton DS (1980) Neuroanatomical bases of spatial memory. Brain Res 200:307-320.

Bland $\mathrm{BH}$, Colom LV (1993) Extrinsic and intrinsic properties underlying oscillation and synchrony in limbic cortex. Prog Neurobiol, in press.

Bliss TVP, Lomo T (1973) Long-lasting potentiation of synaptic transmission in the dentate area of the anaesthetized rabbit following stimulation of the perforant path. J Physiol (Lond) 232:331-356.

Braak H, Braak E (1993) Entorhinal-hippocampal interaction in mnestic disorders. Hippocampus 3:239-246.

Buzsáki G (1986) Hippocampal sharp waves: their origin and significance. Brain Res 398:242-353.

Buzsáki G (1989) Two-stage model of memory trace formation: a role for 'noisy' brain states. Neuroscience 31:551-570.

Buzsáki G, Leung LS, Vanderwolf $\mathrm{CH}$ (1983) Cellular basis of hippocampal EEG in the behaving rat. Brain Res 6:139-171.

Buzsáki G, Horváth Z, Urioste R, Hetke J, Wise K (1992) High frequency network oscillation in the hippocampus. Science 10251027.

Buzsáki G, Bragin A, Chrobak JJ, Nádasy Z, Sik A, Hsu M, Ylinen A (1994) Oscillatory and intermittent synchyrony in the hippocampus: relevance to memory trace formation. In: Temporal coding in the brain (Buzsáki G, Llinás R, Singer W, Berthoz A, Christen Y, eds), in press. New York: Springer.

Chagnac-Amitai Y, Luhmann HJ, Prince DA (1990) Burst generating and regular spiking layer 5 pyramidal neurons of rat neocortex have different morphological features. J Comp Neurol 296:598-613.

Cho YH, Beracochea D, Jaffard R (1993) Extended temporal gradient for the retrograde and anterograde amnesia produced by ibotenate entorhinal cortex lesions in mice. J Neurosci 13:1759-1766.

Chrobak JJ, Buzsáki G (1994) Distinct, behaviorally-regulated, highfrequency oscillations synchronize the input and output connections of the hippocampal-retrohippocampal axis in the rat. Soc Neurosci Abstr.

Chrobak JJ, Napier TC (1992a) Antagonism of GABAergic trans- mission with the septum disrupts working/episodic memory in the rat. Neuroscience 47:833-841.

Chrobak JJ, Napier JJ (1992b) Intraseptal gabaergic infusions disrupt memory in the rat: method and mechanisms. In: Neurotransmitter interactions and cognitive function (Levin E, Decker M, Butcher L, eds), pp 287-300. Boston: Birkhauser.

Chrobak JJ, Vi AL, Buzsáki G (1994) Septal regulation of hippocampal-entorhinal network: memory formation and failure. In: Neurobehavioral plasticity: learning, development and response to brain insults (Spear N, Spear L, Woodruff M, eds), in press. Hillsdale, NJ: Erlbaum.

Churchland PS, Sejnowski TJ (1992) The computational brain. Cambridge, MA: MIT Press.

Connors BW (1984) Initiation of synchronized neuronal bursting in neocortex. Nature 310:685-687.

Deadwyler SA, West JR, Cotman CW, Lynch X (1975) Physiological studies of the reciprocal connections between the hippocampus and entorhinal cortex. Exp Neurol 49:35-37.

Eckhorn R, Obermueller A (1993) Single neurons are differently involved in stimulus-specific oscillations in cat visual cortex. Exp Brain Res 95:177-182.

Finch DM, Wong EE, Derian EL, Babb TL (1986) Neurophysiology of limbic system pathways in the rat: projections from the subicular complex and hippocampus to the entorhinal cortex. Brain Res 397 : 205-213.

Finch DM, Tan AM, Isokawa-Akesson M (1988) Feedforward inhibition of the rat entorhinal cortex and subicular complex. J Neurosci 8:2213-2226.

Freeman WJ (1975) Mass action in the nervous system. New York: Academic.

Gallyas F, Guldner FH, Zoltay G, Wolff JR (1990) Golgi-like demonstration of "dark" neurons with an argyrophil III method for experimental neuropathology. Acta Neuropathol (Berl) 79:620-628.

Gold PE, McGaugh JL (1974) A single-trace, tow-process view of memory storage processes. In: Short-term memory (Deutsch D, Deutsch JA, eds), pp 356-375. New York: Academic.

Grastyán E, Lissák K, Madarász I, Donhoffer H (1959) Hippocampal electrical activity during the development of conditioned reflexes. Electroencephalogr Clin Neurophysiol 11:409-430.

Gray CM (1993) Rhythmic activity in neuronal systems: insights into integrative functions. In: Studies in the sciences of complexity (Nadel L, Stein D, eds). Reading, MA: Addison-Wesley.

Green JD, Arduini AA (1954) Hippocampal electrical activity in arousal. J Neurophysiol 17:533-557.

Gustafsson B, Wigström H (1990) Basic features of long-term potentiation in the hippocampus. Semin Neurosci 2:321-333.

Hebb DO (1949) The organization of behavior. New York: Wiley.

Heinemann U, Zhang CL, Eder C (1993) Entorhinal cortex-hippocampal interactions in normal and epileptic temporal lobe. Hippocampus 3:89-98.

Hyman BT, Van Hoesen GW, Damasio AR, Barnes CL (1984) Alzheimer's disease: cell-specific pathology isolates the hippocampal formation. Science 225:1168-1170.

Ishizuka N, Weber J, Amaral D (1991) Organization of intrahippocampal projections originating from CA3 pyramidal cells in the rat. J Comp Neurol 295:580-623.

Jones RSG (1993) Entorhinal-hippocampal connections: a speculative view of their function. Trends Neurosci 16:58-64.

Jones RSG, Heinemann U (1988) Synaptic and intrinsic responses of medial entorhinal cortical cells in normal and magnesium-free medium in vitro. J Neurophysiol 59:1476-1496.

Jones RSG, Lambert JDC (1990) The role of excitatory amino acid receptors in the propagation of epileptiform discharges from the entorhinal cortex to the dentate gyrus in vitro. Exp Brain Res 80:310322.

Kirk IJ, McNaughton N (1991) Supramammillary cell firing and hippocampal rhythmical slow activity. Neuroreport 2:723-725.

Klink R, Alonso A (1993) Ionic mechanisms for the subthreshold oscillations and differential electroresponsiveness of medial entorhinal cortex layer II neurons. J Neurophysiol 70:144-157.

Köhler C (1985a) Intrinsic projections of the retrohippocampal region in the rat brain. I. The subicular complex. J Comp Neurol 236:504522.

Köhler C (1985b) Intrinsic projections of the retrohippocampal region in the rat brain. II. The medial entorhinal area. J Comp Neurol 246: 149-169. 
Köhler C, Wu J-Y, Chan-Palay V (1985) Neurons and terminals in the retrohippocampal region in the rat's brain identified by anti- $\gamma$ aminobutyric acid and anti-glutamic acid decarboxylase immunocytochemistry. Anat Embryol (Berl) 173:35-44.

Kocsis B, Vertes RP (1992) Dorsal raphe neurons: synchronous discharge with the theta rhythm of the hippocampus in the freely behaving rat. J Neurophysiol 68:1463-1467.

Lee MG, Chrobak JJ, Sik A, Wiley RG, Buzsáki G (1994) Hippocampal theta activity following selective lesion of the septal cholinergic system. Neuroscience, in press.

Leung LS (1984) Model of gradual phase shift of the theta rhythm in the rat. J Neurophysiol 52:1051-1065.

Li Xi-G, Somogyi P, Llinen A, Buzsáki G (1993) The hippocampal CA3 network: an in vivo intracellular labeling study. J Comp Neurol 338:1-29.

Lingenhohl K, Finch DM (1991) Morphological characterization of rat entorhinal neurons in vivo: soma-dendritic structure and axonal domains. Exp Brain Res 84:57-74.

Lopes da Silva FH, Witter MP, Boeijinga PH, Lohman AHM (1990) Anatomical organization and physiology of the limbic cortex. Physiol Rev 70:453-511.

Lorente de Nó R (1934) Studies on the structure of the cerebra cortex. II. Continuation of the study of the ammonic system. J Psychol Neurol 46:113-117.

Mattson MP, Barger SW (1993) Roles for calcium signaling in structural plasticity and pathology in the hippocampal system. Hippocampus 3:73-88.

Mitchell SJ, Ranck JB Jr (1980) Generation of theta rhythm in entorhinal cortex of freely moving rats. Brain Res 189:49-66.

Mitchell SJ, Rawlins JNP, Steward O, Olton DS (1982) Medial septal area lesions disrupt theta rhythm and cholinergic staining in medial entorhinal cortex and produce impaired radial arm maze behavior in rats. J Neurosci 2:292-302.

Otto T, Eichenbaum H, Weiner SL, Wible CG (1991) Learning-related patterns of CAI spike trains parallel stimulation parameters optimal for inducing hippocampal long term potentiation. Hippocampus 1:181192.

Paré D, deCurtis M, Llinás R (1992) Role of hippocampal-entorhinal loop in temporal lobe epilepsy: extra- and intracellular study in the isolated guinea pig brain in vitro. J Neurosci 12:1867-1881.

Paxinos P, Watson C (1986) The rat brain in stereotaxic coordinates. Sydney: Academic.

Petsche H, Stumpf C, Gogolak P (1962) The significance of the rabbitis septum as a relay station between the midbrain and the hippocampus: I. The control of hippocampus arousal activity by the septum cells. Electroencephalogr Clin Neurophysiol 14:202-211.

Quirk GJ, Muller RU, Kubie JL, Ranck JB Jr (1992) The positional firing properties of medial entorhinal neurons: description and comparison with hippocampal place cells. J Neurosci 12:1945-1963.

Rutecki PA, Grossman RG, Armstrong D, Irish-Loewen S (1989) Electrophysiological connections between the hippocampus and entorhinal cortex in patients with complex partial seizures. J Neurosurg 70:667-675.

Squire LR (1992) Memory and the hippocampus: a synthesis from findings with rats, monkeys and humans. Psychol Rev 99:195-231.

Steriade M, Buzsáki G (1990) Parallel activation of thalamic and cortical neurons by brainstem and basal forebrain cholinergic neu- rons. In: Brain cholinergic system (Steriade B, Biesold D, eds), pp 3-62. New York: Oxford UP.

Steriade M, McCormick DA, Sejnowski TJ (1993) The sleeping and aroused brain: thalamocortical oscillations in neurons and networks. Nature 262:679-685.

Steward O, Scoville SA (1976) Cells of origin of entorhinal cortical afferents to the hippocampus and fascia dentata of the rat. J Comp Neurol 169:347-370.

Stewart M, Fox SE (1989) Two populations of rhythmically bursting neurons in rat medial septum are revealed by atropine. J Neurophysiol 61:982-993.

Stewart M, Wong RKS (1993) Intrinsic properties and evoked responses of guinea pig subicular neurons in vitro. J Neurophysiol 70: 232-245.

Stewart M, Quirk GJ, Barry M, Fox SE (1992) Firing relation of medial entorhinal neurons to the hippocampal theta rhythm in urethane anesthetized and walking rats. Exp Brain Res 90:21-28.

Suzuki SS, Smith GK (1985) Single-cell activity and synchronous bursting in the rat hippocampus during waking behavior and sleep. Exp Neurol 89:71-89.

Suzuki SS, Smith GK (1987) Spontaneous EEG spikes in the normal hippocampus. I. Behavioral correlates, laminar profiles and bilateral synchrony. Electroencephalogr Clin Neurophysiol 67:348-359.

Swanson LW, Köhler C (1986) Anatomical evidence for direct projections from the entorhinal area to the entire cortical mantle in the rat. J Neurosci 6:3010-3023.

Traub RD, Miles R (1991) Neuronal networks of the hippocampus. New York: Cambridge UP.

Traub RD, Wong RKS (1982) Cellular mechanism of neuronal synchronization in epilepsy. Science 216:745-747.

Traub RD, Miles R, Buzsáki G (1992) Computer simulations of carbachol-driven rhythmic population oscillations in the $\mathrm{CA} 3$ region of the in vitro rat hippocampus. J Physiol (Lond) 451:653-672.

Urioste R, Chrobak JJ, Buzsáki G (1992) Physiological classification of hippocampal feedback and feedforward interneurons. Soc Neurosci Abstr 18:1.

Van Groen T, Wyss JM (1990) Extrinsic projections from area CA1 of the rat hippocampus: olfactory, cortical, subcortical and bilateral hippocampal formation projections. J Comp Neurol 302:515-528.

Van Hoesen GW, Pandya DN (1975) Some connections of the entorhinal (area 28) and perirhinal (area 35) cortices of the rhesus monkey. III. Efferent connections. Brain Research 95:39-59.

Van Hoesen GW, Hyman BT, Damasio AR (1991) Entorhinal cortex pathology in Alzheimer's disease. Hippocampus 1:1-8.

Vertes R (1986) Brainstem modulation of the hippocampus: anatomy, physiology and significance. In: The hippocampus, Vol 4 (Isaacson RL, Pribram KH, eds), pp 41-75. New York: Plenum.

Wang Z, McCormick DA (1993) Control of firing mode of corticotectal and corticopontine layer $\mathrm{V}$ burst-generating neurons by norepinephrine, acetylcholine and 1S,3R-ACPD. I Neurosci 13:2199-2216.

Witter MP, Groenewegen HJ, Lopes da Silva FH, Lohman AHM (1989) Functional organization of the extrinsic and intrinsic circuitry of the parahippocampal region. Prog Neurobiol 33:161-253.

Zola-Morgan S, Squire LR, Amaral DG, Suzuki WA (1989) Lesions of perirhinal and parahippocampal cortex that spare the amygdala and hippocampal formation produce severe memory impairment. J Neurosci 9:4355-4370. 